\title{
Potential challenges in conducting clinical trials with mixed methods approach
}

Ibnas $\mathrm{M}^{1 *}$, Asim $\mathrm{M}^{2}$, Sathian $\mathrm{B}^{3}$

*Corresponding author:

${ }^{1}$ Mr. Muhamed Ibnas, BSc, Research Coordinator, Clinical Research, Trauma Surgery, Surgery Department, Hamad General Hospital, Doha, Qatar

Email: muhamedibnas@gmail.com, $\underline{\text { ORCID }}$

2,3 Academic Research Associate, Clinical Research, Trauma Surgery, Surgery Department, Hamad General Hospital, Doha, Qatar

\section{Information about the article:}

Received: Jan. 17, 2019

Accepted: Feb. 20, 2019

Published online: Dec. 27, 2019

\section{Publisher}

Nepal Health Research Society, Bahundhara -6, Gokarnesowor Municipality, Kathmandu, Nepal eISSN 2382-5545, ISSN 2676-1343 (Print)

(C) The Author(s). 2019

Content licensing: CC BY 4.0

\section{ABSTRACT}

\section{Background}

Clinical trial is being conducted to assess the safety, efficacy and/or dosage regimen of a drug or therapeutic intervention in human subjects which are carefully selected on predetermined criteria. On the other hand, qualitative research is open-ended focuses on the depth of understanding of issues that are beyond the scope of quantitative analysis. Although, quantitative method is predominated in clinical research; over the past decade qualitative approach is being recognized for its value and unique contributions and is increasingly incorporated in clinical research. The combination of these two approaches in a single study is referred as Mixed Method design. Herein, we aim to explore the major challenges and pitfalls in conducting clinical trials with mixed method approach.

\section{Materials and methods}

We reviewed the published literature in English language through the research engines (PubMed and Google Scholar) involving clinical trials/studies with mixed method approach to look for the potential challenges and issues identified during the conduct of mixed method research (MMR).

\section{Results}

There are various issues in conducting clinical trials with mixed methods approach as it is time consuming, requires expertise, skills and methodological training for both quantitative and qualitative research. Also, there are a number of challenges observed while conducting MMR, such as obtaining informed consent, safety events reporting, data retrieval, study documentation, data confidentiality and storage, inappropriate integration and interpretation of the data as well as incorrect ordering, preferences and objective of each method.

\section{Conclusion}

Use of hybrid approach in clinical trial can provide deeper understanding and insights of research question with higher validity and reliability. MMR has certain challenges which can be overcome by in-depth methodological training and collaboration. Therefore, strong collaboration between clinical and social scientists in necessary to design a competitive funding grant for mixed method research. Finally, integration and implementation of MMR is crucial for conducting pragmatic trials.

\section{Keywords}

Clinical trials, challenges, implementation, mixed methods approach, 